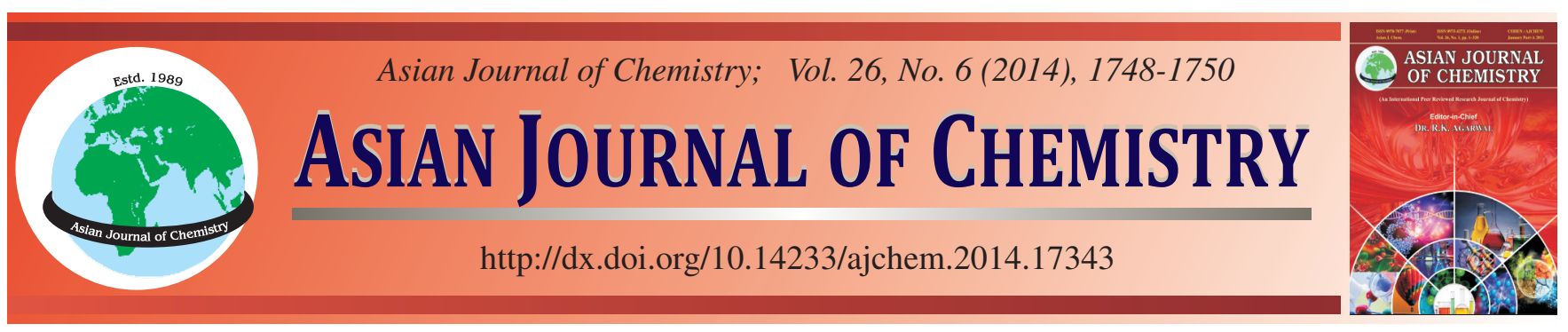

\title{
A New Type of Time-Temperature Integrator Based on Doping Front Migration in Conductive Polymers $\dagger$
}

\begin{abstract}
XIANGlong Wan ${ }^{1, *}$ and Meinhard KNOLL ${ }^{2, *}$
${ }^{1}$ School of Materials Science and Engineering, Anhui University of Science and Technology, Huainan 232001, Anhui Province, P.R. China ${ }^{2}$ Institut für PhysikalischeChemie, Universität Münster , 48149 Münster, Germany

*Corresponding author: Fax: +86 554 6668649; E-mail: xlwan@aust.edu.cn; knoll@uni-muenster.de

Published online: 10 March 2014;

AJC-14884

A new type of time-temperature integrator based on doping front migration is reported in this study. The migration length of the doping front in a mixed water-borne polyaniline and hydrophilic polymer layer integrates the information of time and temperature. The result shows that the migration length is a function of time and temperature. This new type of time-temperature integrator is a thermo-sensitive system that can show the quality change of food and its shelf life well.

Keywords: Time-temperature integrator, Doping front migration, Water-borne polyaniline, Chemical doping.
\end{abstract}

\section{INTRODUCTION}

A time-temperature integrator (TTI) can be used to show the quality change of products in the food and medical industry ${ }^{1-4}$. Time-temperature integrators are produced with different mechanisms for a best-before date label. The diffusion of a colourful solution is applied in $3 \mathrm{M}^{\mathrm{TM}}$ Freeze Watch ${ }^{\mathrm{TM}}$ and MonitorMark ${ }^{\mathrm{TM}}$ time-temperature integrator. A polymerization with colour changing is applied in Lifelines Inc.'s FreshCheck. Photochromic ${ }^{5-7}$, an enzyme ${ }^{8-13}$ with a reaction or $\mathrm{pH}$ indicator ${ }^{14,15}$ which is like Vitsab's CheckPoint ${ }^{\circledR}$ were studied and applied in different time-temperature integrators for chilled foods ${ }^{1-3,5,16-18}$ and medicines ${ }^{4,19}$. All these time-temperature integrators could show the integral information of time and temperature with a changing of colour ${ }^{17,20,21}$.

Polyaniline is a conductive polymer that can show different colours of different states doped by acid or base $\mathrm{e}^{22-25}$. When a solution diffuses or migrates in a hydrophilic polymer, there is a sharp moving front of the solution ${ }^{26-29}$. Integrating these two phenomena, smart labels were reported based on chemical doping $^{30-32}$ and electrochemical doping ${ }^{33}$. To a time-temperature integrator, the front of the indicator should be sharp, visible and distinguishable. The location of the moving front integrates the time and temperature and can display the best-before date and the shelf life. To fit such requirements, we present a new type of time-temperature integrator which is designed to operate with a sharp chemical doping front in a thin mixed conductive polymer film. It can be used in broad areas and gives a low cost choice.

\section{EXPERIMENTAL}

Preparation of time-temperature integrator with a conductive polymer blend: A time-temperature integrator with a conductive polymer blend consists of a substrate (polyethylene terephthalate), a layer of a polymer blend and an encapsulation ( $\mathrm{GBC}^{\circledR}$ document pouch or a clear coating). The polymer blend is prepared from a mixed polymer solution on the substrate with a Mayer bar. The polymer solution is blended with a polyvinyl alcohol (PVA, $72000 \mathrm{~g} / \mathrm{mol}$, Carl Roth.) solution, 2-hydroxyethyl cellulose (HEC, 90000 g/mol, SigmaAldrich) solution and a water-borne polyaniline (NS09/205W, Printcolour AG Switzerland) solution. The thickness of this mixed film is determined by the size of the Mayer bar and the solid content in the solution. A cross-sectional view of the time-temperature integrator with a doping front is shown in Fig. 1.

This time-temperature integrator contains a substrate, a polymer blend layer and anencapsulation. The different layers in this structure are coated layer by layer and sealed in a pouch.

Activation and measurement: This time-temperature integrator can be activated in a $\mathrm{NaOH}$ aqueous solution which

†Presented at The 7th International Conference on Multi-functional Materials and Applications, held on 22-24 November 2013, Anhui University of Science \& Technology, Huainan, Anhui Province, P.R. China 


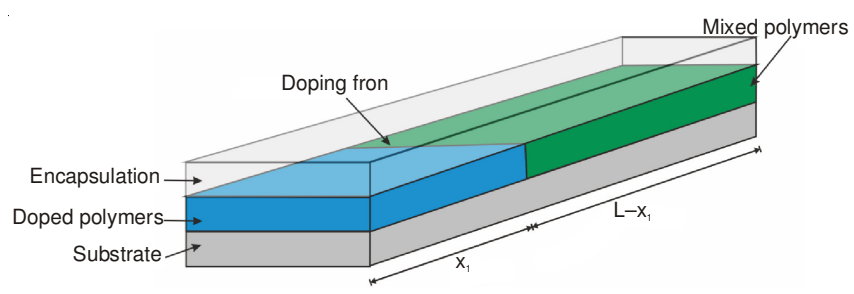

Fig. 1. Cross-sectional view of the time-temperature integrator with a polymer blend

can be sealed in porous materials or a pouch with a thermal sensitive film. When the temperature reaches a critical value, the time-temperature integrator is activated.

Optical measurement: The change of colour in the sandwich structure during chemical doping can be distinguished by the naked eye. The migration lengths are recorded by a scanner in a Thermostatic cabinet at different hours.

\section{RESULTS AND DISCUSSION}

Time dependency of time-temperature integrator: The result of a time-temperature integrator with a $5 \mu \mathrm{m}$ polymer blend layer activated in $0.5 \mathrm{M} \mathrm{NaOH}$ at room temperature $\left(23 \pm 2{ }^{\circ} \mathrm{C}\right)$ is shown in Fig. 2 .
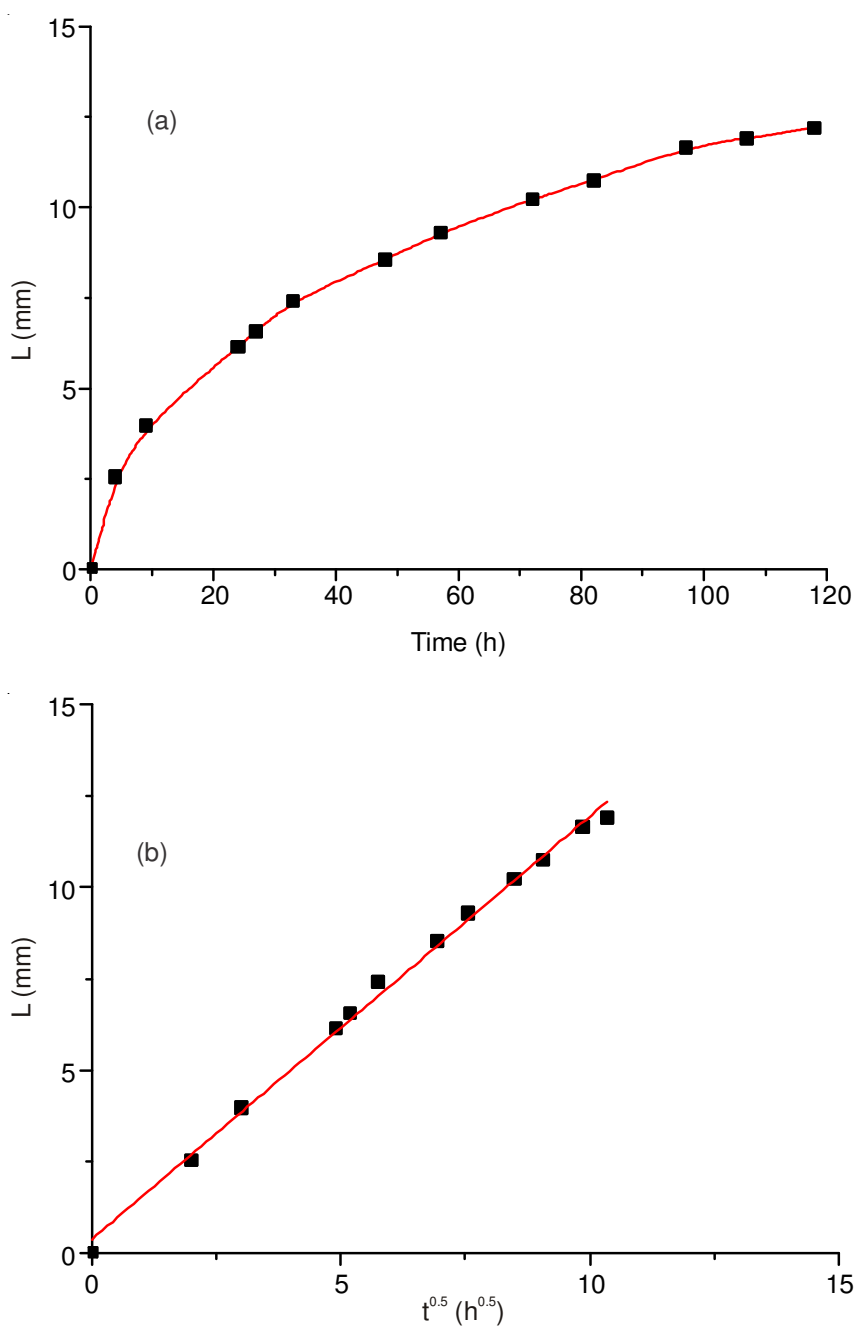

Fig. 2. Time dependencyof time-temperature integrator with a $5 \mu \mathrm{m}$ polymer blend layer at room temperature. (a) migration lengths at different times, (b) migration lengths against the square root of time)
From Fig. 2, it is clear that the time-temperature integrator has a time dependency. The migration length of the doping front in time-temperature integrator is proportional to the square root of time. The coefficient $\left(\mathrm{R}^{2}\right)$ is 0.99 . The migration length (L) follows the law

$$
\mathrm{L}=\mathrm{k} \cdot \sqrt{\mathrm{t}}
$$

$\mathrm{k}$ is the migration coefficient which depends on the materials in the system and the temperature, $\mathrm{t}$ is the time.

Temperature dependency of time-temperature integrator: When the time-temperature integrator is activated at different temperatures, the migration lengths of the doping front at different times are shown in Fig. 3.
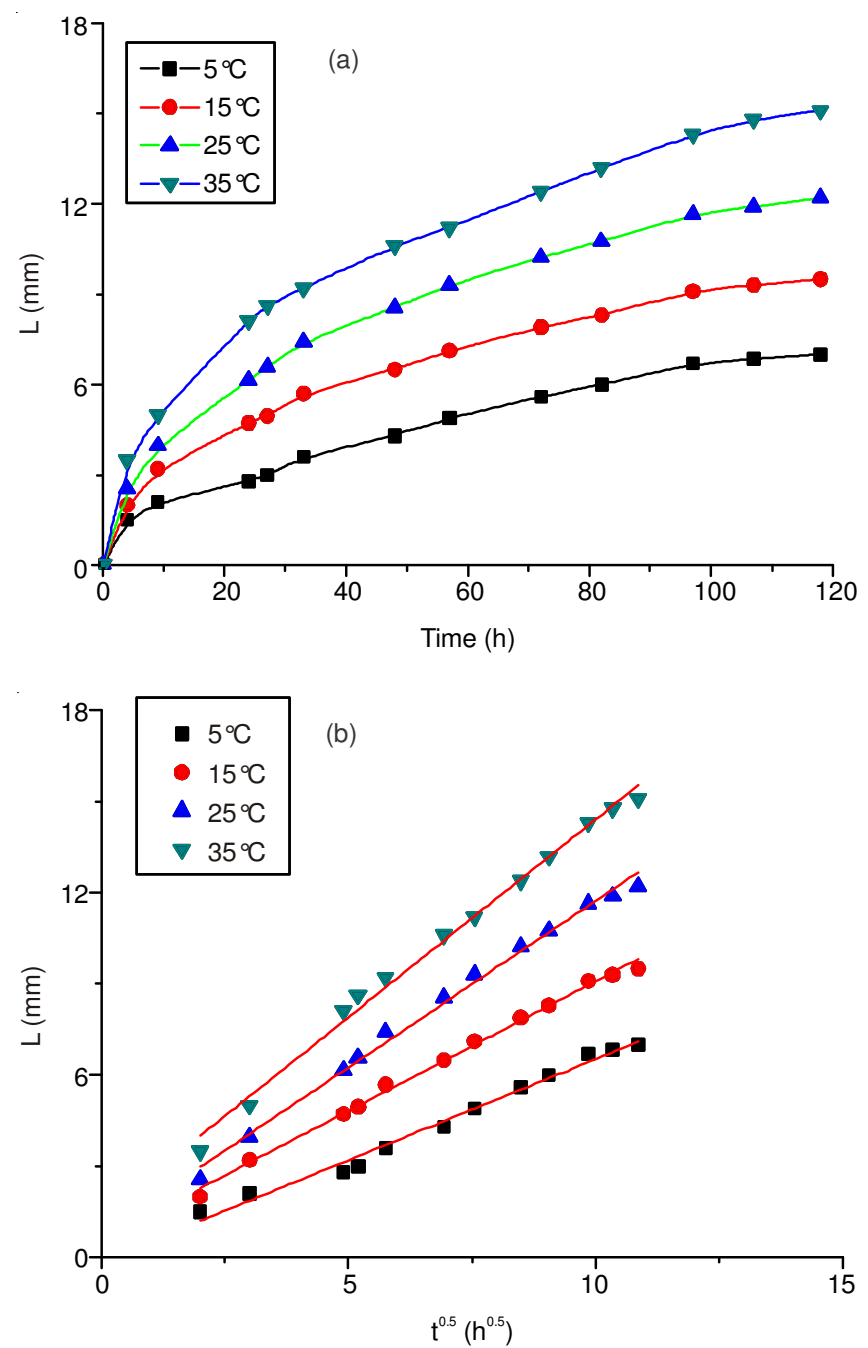

Fig. 3. Temperature dependency of time-temperature integrators with $5 \mu \mathrm{m}$ polymer blend layers at different temperatures. (a) migration lengths at different times, (b) migration lengths against the square root of time)

From Fig. 3, it is obvious that at different temperatures the migration lengths of the doping front in the time-temperature integrator is proportional to the square root of time. All the ccoefficients $\left(\mathrm{R}^{2}\right)$ are around 0.99 . From these results it can be concluded that the time-temperature integrator based on a doping front in a polymer blend layer is a valid device which is sensitive to the time and temperature from 5 to $35^{\circ} \mathrm{C}$ at least. 
Further work is under way to change the thickness of the polymer blend layer in order to modify the migration velocities.

\section{Conclusion}

According to the above results, the time-temperature integrator based in a doping front migration in polymer blend layers can integrate the information of time and temperature well and has a very sharp doping front which is moving and can be seen at any time. It is a thermo-sensitive system that can indicate the quality change of food and the shelf life well.

\section{ACKNOWLEDGEMENTS}

This work is part of the 'Science-to Business PreSeed'project 'ElektronischesMindesthaltbarkeitsdatum' which is supported by the state of North Rhine-Westphalia (Germany) and the European Commission (EFRE). It is also supported partly by the Research Fund for the Doctor (11021) of Anhui University of Science and Technology.

\section{REFERENCES}

1. L.X. Lu, W. Zheng, Z. Lv and Y. Tang, Packaging Technol. Sci., 26, 80 (2013).

2. R. Simpson, S. Almonacid, H. Nuñez, M. Pinto, A. Abakarov and A. Teixeira, J. Food Process Eng., 35, 742 (2012).

3. B.-S. Lee and H.-S. Shin, Food Sci. Biotechnol., 21, 1483 (2012).

4. M. Maschietti, Recent Patents on Eng., 4, 129 (2010).

5. N. Mai, H. Audorff, W. Reichstein, D. Haarer, G. Olafsdottir, S.G. Bogason, J. Kreyenschmidt and S. Arason, Int. J. Food Sci. Technol., 46, 297 (2011)

6. J. Kreyenschmidt, H. Christiansen, A. Hübner, V. Raab and B. Petersen, Int. J. Food Sci. Technol., 45, 208 (2010).

7. H.R. Bhattacharjee, J. Agric. Food Chem., 36, 525 (1988).

8. A. VanLoey, A. Arthawan, M. Hendrickx, T. Haentjens and P. Tobback, Food Sci. Technol.-Lebensm.-Wissen. Technol., 30, 94 (1997).

9. A.M. VanLoey, T.H. Haentjens, M.E. Hendrickx and P.P. Tobback, Food Biotechnol., 11, 147 (1997).
10. A.M. VanLoey, T.H. Haentjens, C. Smout, M.E. Hendrickx and P.P. Tobback, Food Biotechnol., 11, 169 (1997).

11. S. Tsoka, P.S. Taoukis, P. Christakopoulos, D. Kekos and B.J. Macris, Food Biotechnol., 12, 139 (1998).

12. K. Kim, E. Kim and S.J. Lee, J. Food Eng., 113, 118 (2012).

13. E. Kim, K. Kim, Y.A. Kim and S.J. Lee, Food Sci. Biotechnol., 21, 1451 (2012).

14. M.J. Kim, S.W. Jung, H.R. Park and S.J. Lee, J. Food Eng., 113, 471 (2012).

15. H. Vaikousi, C.G. Biliaderis and K.P. Koutsoumanis, Int. J. Food Microbiol., 133, 272 (2009).

16. W. Kim, W.Y. Choe and K.W. Hong, J. Korean Soc. Appl. Biol. Chem., 55, 535 (2012).

17. G.A. Seisenbaeva, E. Ilina, S. Håkansson and V.G. Kessler, J. Sol-Gel Sci. Technol., 55, 1 (2010).

18. H.J. Park, S.-D. Shim, S.-G. Min and S.-J. Lee, Korean J. Food Sci. An. Res., 29, 349 (2009).

19. G.E. Harris, S. Cloud and B.A. Myhre, Transfusion, 17, 282 (1977).

20. W. Krysiak, R. Adamski and D. Zyzelewicz, J. Food Qual., 36, 21 (2013).

21. G.J. Favetto, J. Chirife, O. C. Scorza and C. Hermida, J. Food Prot., 51, 542 (1988).

22. A.K. Haghi, J. Balkan Tribological Association, 15, 141 (2009).

23. H. Tsubakihara, T. Shimakawa and K. Hayashi, Kobunshi Ronbunshu, 56, 746 (1999).

24. Y. Haba, E. Segal, M. Narkis, G.I. Titelman and A. Siegmann, Synth. Met., 106, 59 (1999).

25. S.A. Chen and G.W. Hwang, J. Am. Chem. Soc., 117, 10055 (1995).

26. P.F. Nealey, R.E. Cohen and A.S. Argon, Polymer, 36, 3687 (1995).

27. C.J. Durning, M.M. Hassan, H.M. Tong and K.W. Lee, Macromolecules, 28, 4234 (1995).

28. M. Best, J.W. Halley, B. Johnson and J.L. Vallés, J. Appl. Polym. Sci., 48, 319 (1993).

29. D.S. Cohen and A.B. White, J. Polym. Sci. B, Polym. Phys., 27, 1731 (1989).

30. M. Knoll, Electrochim. Acta, 54, 216 (2008).

31. J. Hermes and M. Knoll, Electrochim. Acta, 54, 4258 (2009).

32. M. Nolte, X. Wan, O. Kopp, I. Hermes, J. Panz, A. Rahmanian and M. Knoll, Electrochim. Acta, 56, 2983 (2011).

33. P. Tehrani, I. Engquist, N.D. Robinson, D. Nilsson, M. Robertsson and M. Berggren, Electrochim. Acta, 55, 7061 (2010). 